\title{
Census of dinosaur skin reveals lithology may not be the most important factor in increased preservation of hadrosaurid skin
}

\author{
Matt Davis \\ Acta Palaeontologica Polonica 59 (3), 2014: 601-605 doi: http://dx.doi.org/10.4202/app.2012.0077
}

A global census of published records of dinosaur skin from the Mesozoic, cross-referenced against a more detailed lithological dataset from the Maastrichtian of North America, clarifies why most examples of fossilized dinosaur skin come from hadrosaurids. Globally, more published specimens of hadrosaurids exhibit preserved skin than any other major clade of dinosaur. North American Maastrichtian hadrosaurid fossils are 31 times more likely to have skin preserved than coeval dinosaur remains. This does not arise from collection methodology, the large population size of hadrosaurids, or the gross lithology of their depositional environment. The reason that so many hadrosaurid fossils have skin is still elusive, but was likely something intrinsic to hadrosaurids that originated early on in the clade, perhaps the possession of tougher or thicker skin. The database of published examples of fossilized dinosaur skin assembled here will assist the continued development of a much needed common terminology and taxonomic framework for dinosaur skin.

Key words: Dinosauria, hadrosaurid, skin, exceptional preservation, soft tissue fossils, Mesozoic, North America.

Matt Davis [matthew.davis@yale.edu], Department of Geology and Geophysics, Yale University, New Haven, Connecticut, 06520, USA.

This is an open-access article distributed under the terms of the Creative Commons Attribution License (for details please see creativecommons.org), which permits unrestricted use, distribution, and reproduction in any medium, provided the original author and source are credited. 
FoF $\underline{\text { Supplementary file }(16.1 \mathrm{kB})}$ 